\title{
Problems in Implementation of the Spatial Plan of the Republic of Srpska until 2015 - Quantitative Analysis
}

\author{
Branislav Bijelić ${ }^{A *}$, Dejan Đorđević ${ }^{B}$ \\ Received: July 9, 2017 | Revised: October 3, 2017 | Accepted: October 28, 2017 \\ DOI: $10.5937 / g p 21-16077$
}

\begin{abstract}
The implementation of spatial plans in the Republic of Srpska is certainly the weakest phase of the process of spatial planning in this entity. It is particularly evident in the case of the Spatial Plan of the Republic of Srpska until 2015 which is the highest strategic spatial planning document in the Republic of Srpska. More precisely, the implementation of spatial plans has been defined as the carrying out of spatial planning documents, i.e. planning propositions as defined in the spatial plans. For the purpose of this paper, a quantitative analysis of the implementation of the planning propositions envisioned by this document has been carried out. The difference between what was planned and what was implemented at the end of the planning period (ex-post evaluation of planning decisions) is presented in this paper. The weighting factor is defined for each thematic field and planning proposition, where the main criterion for determining the weighting factor is the share of the planning proposition and thematic field in the estimated total costs of the plan (financial criterion). The paper has also tackled the issue of the implementation of the Spatial Plan of Bosnia and Herzegovina for the period $1981-2000$, as well as of the Spatial Plan of the Republic of Srpska 1996 - 2001 - Phased Plan for the period 1996 - 2001, as the previous strategic spatial planning documents of the highest rank covering the area of the Republic of Srpska. The research results have proven primary hypothesis of the paper that the level of the implementation of Spatial Plan of the Republic of Srpska until 2015 is less than 10\%.
\end{abstract}

Keywords: implementation, spatial plan, planning proposition, quantitative analysis, ex-post evaluation

\section{Introduction}

Implementation is the term used in a variety of disciplines (computer science, economics, political science), which generally has a similar meaning arising from its basic meaning in Latin - adimpleo, and it is fulfillment, carrying out or execution. The difference between the above disciplines is related to the object of implementation - software/hardware, idea, model, legal act, standard, project, policy or plan. Stefanović and Milić (2012) assume that implementation implies in the wider sense carrying out, execution, application or realisation of any agreement, decision or plan. Some authors, instead of the implementation of plan, use just a term "carrying out of a plan" (Perišić, 1985). According to them the plan is "the commitment for long-term, patient and persistent carrying out of the plan" (Marinović-Uzelac, 2001). Marija Maksin-Mićić highlights Faludi's understanding, that an implementation or application is associated with the regulatory plans that are directive, while the strategic plans (spatial and urban plans) are connected with a term "performance", because of their indicative nature (Maksin-Mićić, 2002).

Theorists of rational planning observe implementation plans as the last stage in the planning process, or

\footnotetext{
A Urbis centar Ltd. Banja Luka, Bulevar vojvode Stepe Stepanovića 101a, Banja Luka, Republic of Srpska, Bosnia and Herzegovina

B University of Belgrade, Faculty of Geography, Serbia, Studentski trg 3/III, Belgrade; dejandj@gef.bg.ac.rs

* Corresponding author: Branislav Bijelić, e-mail: bbijelic@urbiscentar.com
} 
phase, which comes at the end of the planning process (Healey, 1979; Redman, 1983; Gunton, 1984).

In the strict sense of the word, the implementation of spatial plans has been defined as the carrying out of the solutions envisaged by spatial planning documents, i.e. planning propositions defined in spatial plans. The effectiveness of spatial planning is primarily measured through the implementation of spatial plans. Đorđević (2004) under implementation in spatial planning implies the micro organizational behavior that explains the way of defining and using policies, spatial allocation of resources and revenues from these activities. Stefanović (2011) highlights that implementation includes both the planning and postplanning elements. It is a unique, continuous process that does not start with the adoption of the plan by a political authority.

Authors from Bosnia and Herzegovina do not focus their attention to the implementation of spatial planning documents. For instance, Bublin (2000) states that the implementation is the phase following the adoption of the plan, and goes on by saying that "in the case of implementation, appropriate techniques are applied for operationalization, creation of policies, programs and development methods for assessing its success and failure, and reaching development goals". The ambiguity of concepts of implementation instruments, on the one hand, and evaluation of plan implementation, on the other hand, is evident here.

Since the final purpose of spatial planning is the implementation of spatial plans, these strategic spatial planning documents must contain certain models of implementation. These models can be divided into four types:

- model of implementation of spatial planning strategies and policies,

- model of implementation of land protection,

- model of implementation of technical planning propositions,

- model of implementation of rules for land use, spatial arrangement and construction (Stefanović, 2011).

As a reaction to the importance given to this stage in the planning process, planning theories, which put their focus on the plan implementation, have recently been developed. According to these theories, the implementation is the main purpose of the planned action, and the emphasis is put on the political feasibility in evaluation process, i.e. the complexity of the political context (Vujošević, 2004).

Out of all former Yugoslav Republics, the implementation of spatial plans is only properly addressed in the legislation of the Republic of Serbia, where the Law on Planning and Construction (Official Gazette of the Republic of Serbia, No. 72/2009, 81/2009, 64/2010, 24/2011, $121 / 2012,42 / 2013,50 / 2013,98 / 2013,132 / 2014,145 / 2014$ ) forsees the adoption of the implementation program of Spatial Plan of the Republic of Serbia and of the regional spatial plans, as well as the annual reports on the implementation of the above spatial planning documents. In the previous period, in relation to the highest strategic spatial planning document, two implementation programs of the Spatial Plan of the Republic of Serbia (periods 2011-2015 and 2016-2020) and four annual reports on the implementation of the Spatial Plan of the Republic of Serbia (2011, 2012, 2013 and 2014) have been adopted. Unfortunately, these documents do not provide a comprehensive, quantitative assessment of the implementation of the Spatial Plan of the Republic of Serbia. Only in the Report on the Implementation of the Spatial Plan of the Republic of Serbia and the State of Spatial Development in 2014 (Ministry of Construction, Transport and Infrastructure, 2015) it is estimated that looking from the perspective of $40 \%$ of the planning period, only $9 \%$ of the strategic priorities of this planning document were implemented (11 out of 125 strategic projects).

The implementation of spatial plans in the Republic of Srpska and Bosnia and Herzegovina is the least examined phase of the process of spatial planning, which should be a continuous process that starts with the creation of spatial planning document and ends with the implementation of it in practice (in the reality of the given space). Insufficient research of this stage in the process of spatial planning is certainly something that contributes to the insufficient implementation of spatial plans.

\section{Main hypothesis}

The main hypothesis of this paper is that the level of the implementation of the Spatial Plan of the Republic of Srpska until 2015 is below $10 \%$, which means that there is the same level of the implementation of the planning propositions defined by this strategic spatial planning document. In order to confirm this hypothesis, it is necessary to carry out an empirical research (quantitative analysis) on the implementation of the planning propositions of this document, which should precede the analysis of the historical context of the implementation of the strategic spatial planning documents of the highest rank in Bosnia and Herzegovina and the Republic of Srpska respectively.

\section{Material and methods}

\section{Area of interest}

The area of interest of this paper is the implementation of the Spatial Plan of the Republic of Srpska until 2015, an entity (federal-confederal unit) in Bosnia and Herzegovina (BIH). 


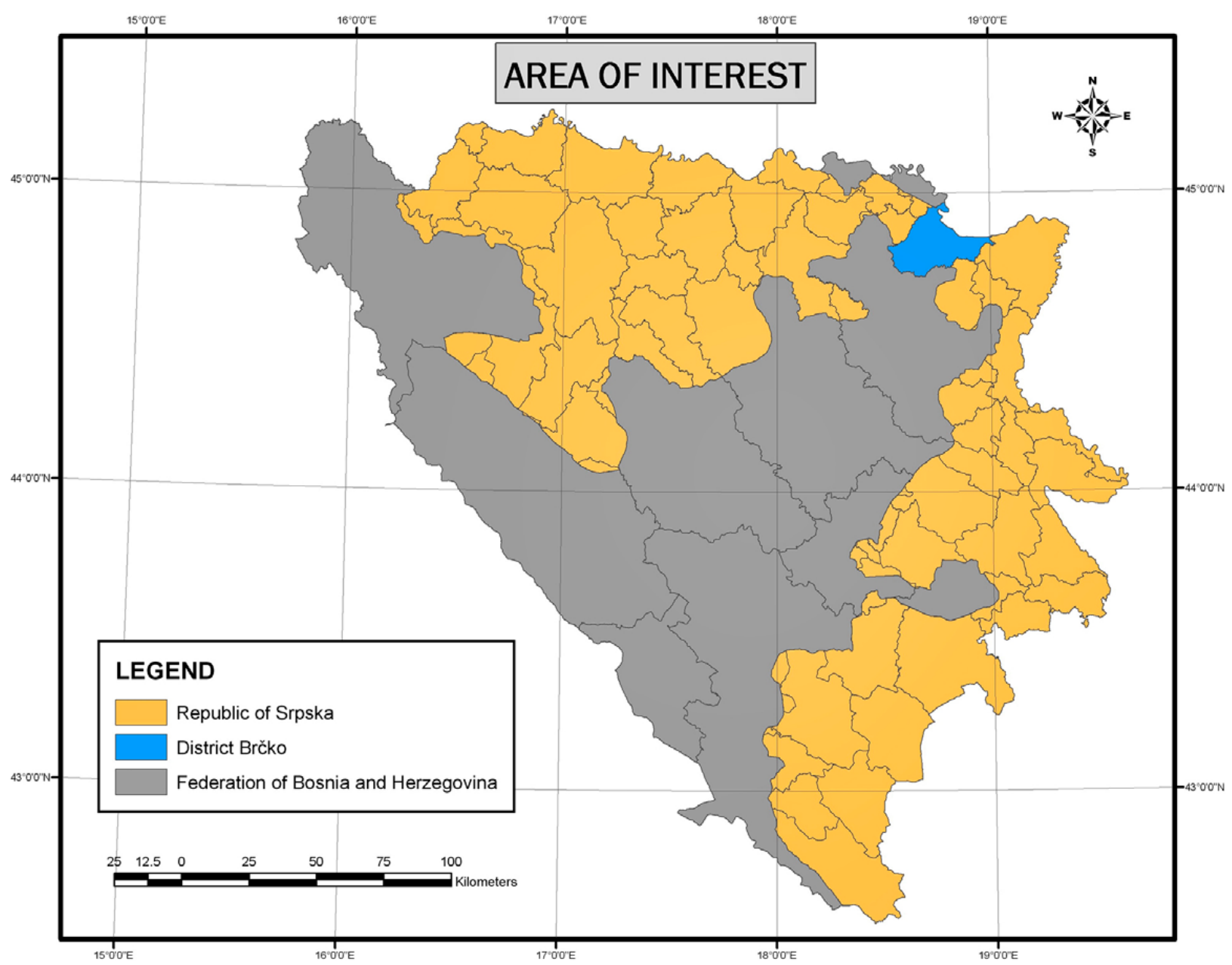

Figure 1. Position of the Republic of Srpska in Bosnia and Herzegovina Source: authors

The Republic of Srpska (RS) covers mainly the northern and eastern part of Bosnia and Herzegovina. Its total area is $24,666 \mathrm{~km}^{2}$ or $48.17 \%$ of the total area of Bosnia and Herzegovina. This entity is located between $45^{\circ} 16^{\prime}$ and $42^{\circ} 33^{\prime}$ north longitude, and between $16^{\circ} 11^{\prime}$ and $19^{\circ} 37^{\prime}$ east latitude (New Institute for Urbanism of the Republic of Srpska, 2015). There are 64 local government units (LGU) in the RS - 57 municipalities and 7 cities (N.B. the City of Istočno Sarajevo is a single local government unit comprising 6 municipalities). The RS has no regional level of government in its administrative division.

The preliminary drafting activities for the Spatial Plan of the Republic of Srpska until 2015 began in August 2003, and ended with the adoption of the plan by the National Assembly of the Republic of Srpska in September 2007.

The main aim of this strategic spatial planning document of the Republic of Srpska is defined as "activation of spatial potential of the Republic of Srpska based on the principles of sustainable development, which will increase its competitiveness and attractiveness for investment and thus create conditions for im- proving living standard up to around \$4,000 of GDP per capita" (Institute for Urbanism of the Republic of Srpska, 2008).

\section{Methodology}

This research is based on a quantitative analysis of the implementation of the Spatial Plan of the Republic of Srpska until 2015, which was adopted in September 2007 (initial date of implementation). The focus of the research is the difference between what was planned and what was finally implemented at the end of the planning period. It is a typical ex-post evaluation of planning decisions. In the case of the Spatial Plan of the Republic of Srpska until 2015 such an ex-post quantitative analysis of the implementation of planning propositions is highly applicable due to its high degree of directivity, which distinguishes it from the strategic spatial planning documents of that rank in the former Yugoslav Republics and Europe. This research is also based on the Spatial Plan of Bosnia and Herzegovina for the period $1981-2000$ and the Spatial Plan of the Republic of Srpska 1996 - 2015 - Phased Plan for the period $1996-2001$ as the previous stra- 
tegic spatial planning documents of the highest rank, which will explain the historical context. Both statistical and comparative methods have been used in this paper.

It is important to note that the level of the implementation of the Plan is primarily evaluated inrespect to the propositions which are clearly stated in the text and/or graphic part of the Spatial Plan of RS until 2015. This approach implies an analysis of the regulatory planning propositions, because it enables their quantitative and cartographic determination (directivity).

Planning propositions are structured by their thematic fields and grouped according to the similarities, where "duplicated" planning propositions are excluded in certain fields (for example hydro-technical infrastructure and the environment), as well as planning propositions that belong to other thematic fields (eg. water and multimodal transport in rail transport). The weighting factor is defined for each thematic field and planning proposition, where the main criteria for determining the weighting factor is the participation of the planning proposition and thematic field in the estimated total costs of implementation of the plan (financial criterion). For example, it is estimated that the costs of implementation of planning propositions in the field of public services (education, culture, social welfare and sport) are approximately 600 million Bosnia and Herzegovina convertible mark (BAM) in total, which is is $2 \%$ of the total sum of the estimated costs for the implementation of the Plan (3o billion BAM), and this value serves as the weighting factor for this thematic field.

Table 1. Weighting factors for determining the level of implementation of the Spatial Plan of the Republic of Srpska until 2015

\begin{tabular}{|l|c|}
\hline Thematic field & $\begin{array}{c}\text { Share of thematic field in } \\
\text { plan - weighting factor (\%) }\end{array}$ \\
\hline Natural resources & 2 \\
\hline $\begin{array}{l}\text { Spatial organization and } \\
\text { system of centers }\end{array}$ & 2 \\
\hline Population & 12.5 \\
\hline Economic activities & 3 \\
\hline Public services & 2 \\
\hline Infrastructure & 75.86 \\
\hline Environment & 2 \\
\hline $\begin{array}{l}\text { Guidelines for } \\
\text { implementation of plan }\end{array}$ & 0.14 \\
\hline Total & 100 \\
\hline
\end{tabular}

Source: authors

Although some prominent authors (Mastop, Faludi, 1997) consider that the above methodological approach is inadequate for strategic plans, since the plans cannot be evaluated only on the basis of their compliance with the final results, in the case of the Spatial Plan of the Republic of Srpska until 2015 it is adequate due to its high degree of directivity, which also contributes to the absence of information and monitoring system of implementation of the strategic spatial planning documents in the RS and $\mathrm{BIH}$, as well as unsatisfactory coverage of spatial plans of lower rank (39\% of spatial plans of local government units and only one spatial plan of special purpose area).

\section{Historical context}

Spatial planning system in Bosnia and Herzegovina until 1992 was a mixture of the planning systems, where the dominant system of planning was based on an integrated approach. In the planning system of Bosnia and Herzegovina the elements of planning with the dominant tradition of urban planning, and planning system based on determination of land use can be identified. Due to the absence of typical regional spatial plans in the legislation of that time, it is not possible to identify the presence of significant elements of the planning system based on the regional - economic approach. This kind of planning system is still evident in the Republic of Srpska (ESPON, 2007).

The first strategic spatial planning document of the highest rank in the territory of Bosnia and Herzegovina was the Spatial Plan of Bosnia and Herzegovina for the period from 1981 to 2000 . This document was finally adopted in January 1982 . Revised text with corrections of certain number of planning solutions was published in 1989. In the Spatial Plan of Bosnia and Herzegovina for the period from 1981 to 2000 , the model of implementation of spatial planning strategies and policies was given special attention to, with certain elements of other two models: model of implementation of land protection, and model of implementation of technical planning propositions. In the middle of the planning period of this strategic spatial planning document, there was a change in the socio - political system (1990 1991), followed by the armed conflict in the period from 1992 to 1995. In addition to these difficult and unpredictable circumstances, the implementation of the Spatial Plan of Bosnia and Herzegovina was satisfactory in the first 10 years of the planning period. This is indicated by the completion of several major infrastructure facilities: thermal power plants Gacko and Ugljevik, hydropower plant Višegrad with associated transmission lines; airports Banja Luka (Mahovljani) and Tuzla (Dubrave) and railway Tuzla (Živinice) - Zvornik. The lowest level of implementation was achieved in the field of road transport and hydro-technical infrastructure. Planned European roads (E-65, E-73, E-661, E-761, E-762) were not realised, and no multi-purpose planned reservoirs (Assembly of SR BIH, 1989) were built. 
The emergence of the Republic of Srpska in 1992 as a specific political - territorial unit (entity) created conditions for the development of the Spatial Plan of the Republic of Srpska. This document is seen as one of the elements of the statehood (independence) of the Republic of Srpska, which should provide opportunities for autonomous territorial development, primarily relying on the neighboring Federal Republic of Yugoslavia (Serbia and Montenegro). The first set of activities for the Plan drafting have started by the adoption of the Decision on development of Spatial plan of the Republic of Srpska in October 1993, and ended with the adoption of the Spatial Plan of the Republic of Srpska for the planning period 1996 - 2015 in the form of a phased plan for the first five-year period (1996 - 2001). This document has adopted some elements of the planning propositions from the previous Spatial Plan of Bosnia and Herzegovina (primarily in the field of hydro-technical infrastructure and natural heritage), but also provided a new set of planning propositions. Though the implementation instruments are much more elaborate than the ones envisioned in the Spatial Plan of Bosnia and Herzegovina, in this strategic spatial planning document, the model of implementation of spatial planning strategies and policies was primarily represented, along with some elements of the model of implementation of land protection and model of implementation of technical planning propositions. However, the implementation of the Spatial Plan of the Republic of Srpska 1996 - 2015 in the first five years of the planning period was almost unnoticable. During this period no planned large infrastructure units (highway, railway, multi-purpose reservoir, pipeline, and power plants) that were envisioned, were materialized. By the end of the first five-year period, activities were started on the development of a new planning document that would, on the basis of a better information base, define the planning propositions for the whole planning period Spatial Plan of the Republic of Srpska until 2015.

\section{Results}

From the perspective of its main goal, i.e. the target value of the gross domestic product (GDP) per capita, the Spatial Plan of the Republic of Srpska until 2015 has reached the predicted value, since the per capita GDP in RS in 2014 in nominal terms amounted to $\$ 4,223$. It should be noted that the GDP/capita in 2003 (initial year of the plan drafting) amounted to $\$ 1,812$, with a significantly higher value of the average annual exchange rate of the US dollar (Republika Srpska Institute of Statistics, 2015). If the 2003 US dollar exchange rate had been used for determining the level of GDP/capita in 2014, the target value would not have been reached.
In addition to the gross domestic product per capita, the plan has predicted values for other significant spatial indicators - the number of inhabitants and the number of new units of housing, and certain telecommunication indicators (number of units of the postal network and the degree of coverage of fixed telephony) by spatial units (units of local governance, and regions). Preliminary data of the 2013 Census clearly show that the total projected number of $1,399,625$ residents in 2015 has not been reached at all. In terms of the number of housing units, it can be estimated that the total projected number of 85,472 new apartments have not only been achieved, but also significantly exceeded (Republika Srpska Institute of Statistics, 2013). On the other hand, the total projected telecommunication indicators have not been accomplished.

Unlike the objectives and indicators, the situation is much clearer when it comes to the planning propositions when they are considered as the essential indicators of implementation. From textual and graphical part of the plan was abstracted the total of 154 planning propositions. Their structure is illustrated in the Figure 2.
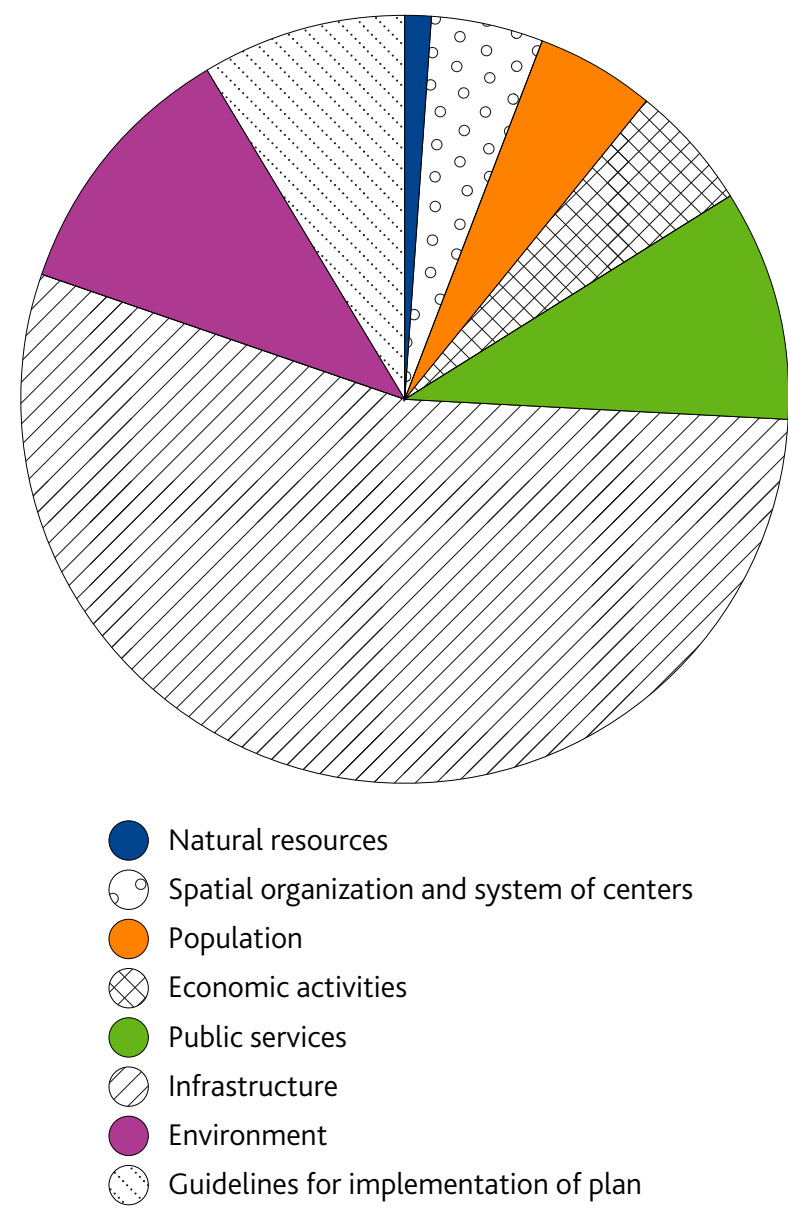

Figure 2. Share of planning propositions from the Spatial Plan of the Republic of Srpska until 2015, by thematic fields Source: authors 


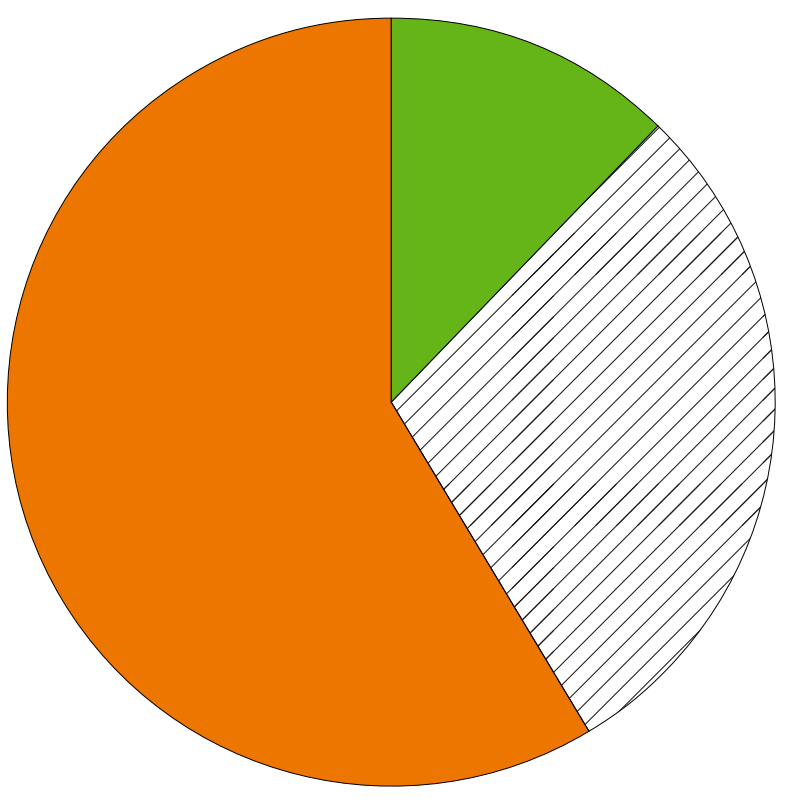

Fully implemented planning propositions

Partially implemented planning propositions Unimplemented planning propositions

Figure 3. Structure of planning propositions from the Spatial Plan of the Republic of Srpska until 2015, by the implementation percentage

Source: authors

The largest share in the total structure of planning propositions is occupied by infrastructural planning propositions $(54.55 \%$ ), followed by planning propositions in the field of the environment and public services (11.04\% and $9.74 \%)$. Natural resources propositions are the least represented with $1.3 \%$, or only two planning propositions.

The quantitative analysis determined that out of the total number of 154 planning propositions, only 19 or $12.34 \%$ have been fully implemented, while 45 planning propositions or $29.22 \%$ are partially implemented. Unimplemented planning propositions have taken up as much as $58.44 \%$ (Figure 3).

Above-average percentage of the implementation of planning propositions is only evident in the thematic field of infrastructure (17.86 \%), and the guidelines for implementation of the plan (15.38\%). The four thematic areas (natural resources, spatial organization and system of centers, economic activities and public services) have recorded not even a single fully implemented planning proposition.

Finally, the total degree (level) of the implementation of planning propositions from the Spatial Plan of the Republic of Srpska until 2015 ammounts to only $5.9 \%$. The following table shows the level of implementation of planning propositions in this by thematic fields.
Table 2. Implementation of planning propositions from the Spatial Plan of the Republic of Srpska until 2015, by thematic fields

\begin{tabular}{|l|c|}
\hline Thematic field & $\begin{array}{c}\text { Degree of implementation } \\
\text { (\%) }\end{array}$ \\
\hline Natural resources & 7.50 \\
\hline $\begin{array}{l}\text { Spatial organization and } \\
\text { system of centers }\end{array}$ & 15.00 \\
\hline Population & 0.72 \\
\hline Economic activities & 1.67 \\
\hline Public services & 10.65 \\
\hline Infrastructure & 6.06 \\
\hline Environment & 23.85 \\
\hline $\begin{array}{l}\text { Guidelines for } \\
\text { implementation of plan }\end{array}$ & 20.97 \\
\hline Total & 5.90 \\
\hline
\end{tabular}

Source: authors

Although the infrastructure planning propositions are individually the most represented and with the highest weighting factor, the degree of their implementation is $6.06 \%$, and they contributed most to the total level of the implementation of the Spatial Plan of the Republic of Srpska until 2015. The lower level of implementation of planning propositions has been recorded in the thematic fields of population (0.72\%) and economic activities (1.67 \%). On the other hand, the highest level of the implementation of planning propositions is present in the thematic fields of the environment $(23.85 \%)$ and, quite reasonably, the guidelines for implementation of plan (20.97\%).

\section{Conclusion}

The research data on the level of the implementation of planning propositions, based on quantitative analysis, clearly indicate that the implementation of the Spatial Plan of the Republic of Srpska until 2015 was very unsatisfactory, as the level of the implementation of the planning propositions envisioned by it was only $5.9 \%$. The largest number of significant planning propositions, primarily large infrastructure objects, have not been implemented. Unfortunately, a similar research of a strategic spatial planning document is very rare in the scientific literature, so it has not been possible to make a better comparison of the level of the implementation between the plans (such an outcome may eventually lead to the categorization of spatial plans according to the level of implementation). However, any kind of activity with $5.9 \%$ degree of implementation can be evaluated as extremely unsuccessful. The research results definitely confirm the basic hypothesis of the paper that the level of the implementation of 
the Spatial Plan of the Republic of Srpska until 2015 is below $10 \%$.

Comparing the above results with previous strategic spatial planning documents on the territory of $\mathrm{BIH}$ and RS, primarily with the Phased Plan from 1996, it is evident that numerous planning propositions were repeated, i.e. they were only redirected from the previous spatial plan into the next spatial plan. This repetition (transfer) of planning propositions leads to the conclusion that the problem regarding the implementation of the spatial planning documents of the highest strategic importance in Bosnia and Herzegovina has been present for almost 35 years. The reasons for such unsuccessful implementation degree are multiple, and generally can be divided into two main types: (1) planning propositions in a narrow sense and (2) the support for the implementation of plan.

Some experts in the field of spatial planning in $\mathrm{BIH}$ justify the large number of unimplemented planning propositions by the need for land marking of specific areas for certain purposes. They claim that these particular documents of space planning have been neither driven by unrealistic and oversized propositions, nor based on groundless needs of space users and actual development. This view of spatial planning, as merely the process of land marking of certain territory, is the consequence of the understanding of spatial planning as physical planning, and all these factors have been reflected in educational and legislational practice in previous years (Law on Spatial Planning, 1974).

However, the fact that a significant number of planning propositions have not been implemented, particularly those that come from the real needs of space users and developmental point of view, indicates that the support for the implementation of the plan was not provided by the political authorities and institutions (Wannop, 1995). A more comprehensive and concrete political support would certainly have a positive impact on the increase of the level of implementation of the Spatial Plan of the Republic of Srpska until 2015.

\section{References}

Assembly of the Socialist Republic of Bosnia and Herzegovina, 1989. Spatial Plan of Bosnia and Herzegovina for the period from 1981 to 2000 (revised text). Assembly of SR BIH, Sarajevo. (in Serbo-Croatian).

Bublin, M. 2000. Spatial Planning. Univerzitetska knjiga, Sarajevo. (in Bosnian).

Đorđević, D. 2004. Introduction to the Theory of Planning. University of Belgrade, Faculty of Geography, Belgrade. (in Serbian).
ESPON, 2007. ESPON Project 2.3.2. Governance of Territorial and Urban Policies from EU to Local Level (Final Report). ESPON, Luxembourg.

Gunton, T. I. 1984. The Role of the Professional Planner. Canadian Public Administration, 27- 3, 399-417.

Healey, D. (1979) On Implementation - Some Thoughts on the Issues Raised by Planners Current Interest in Implementation. In: Implementation-Views from an Ivory Tower, Dept. of Town Planning Working Paper, Oxford Polytehnic, 43, 2-15.

Institute for Urbanism of the Republic of Srpska, 1996. The Spatial Plan of the Republic of Srpska 1996 2001 - Phased Plan for the period 1996 - 2001. Institute for Urbanism of the RS, Banja Luka. (in Serbian).

Institute for Urbanism of the Republic of Srpska, 2008. The Spatial Plan of the Republic of Srpska until 2015. Institute for Urbanism of the RS, Banja Luka. (in Serbian).

Li, T., Tiyan, S. 2011. Evaluation of plan implementation in the transitional China: A case of Guangzhou city master plan. Cities, 28, 11-27.

Maksin-Mićić, M. 2002. The Performance of the Spatial Plan of the Republic Serbia. In: Vujošević, M. [ed.], Contribution to the advancement of the theory and practice of planning and implementation, Institute of Architecture and Urban \& Spatial Planning of Serbia, Belgrade, 117-124 pp. (in Serbian with English summary).

Marinović-Uzelac, A. 2001. Spatial Planning. Dom i svijet, Zagreb. (in Croatian).

Mastop, H., Faludi, A. 1997. Evaluation of strategic plans: the performance principle. Environment and Planning B: Planning and Design, 24, 815-832.

Ministry of Communications and Transport, 2007. Environmental Impact Assessment - a project of the Corridor Vc Highway (Abstract). Ministry of Communications and Transport of BIH, Sarajevo. (in Bosnian).

Ministry of Construction, Transport and Infrastructure, 2015. Report on Implementation of the Spatial Plan of the Republic of Serbia and the State of Spatial Development in 2014. Ministry of Construction, Transport and Infrastructure of the Republic of Serbia, Belgrade. (in Serbian).

New Institute for Urbanism of the Republic of Srps$\mathrm{ka}, 2015$. The changes and amendments to the Spatial Plan of the Republic of Srpska until 2025. New Institute for Urbanism of the RS, Banja Luka. (in Serbian).

Official Gazette of the Republic of Serbia, 2009. Law on Planning and Construction, Belgrade, No. 72/2009, 81/2009, 64/2010, 24/2011, 121/2012, 42/2013, 50/2013, 98/2013, 132/2014, 145/2014. (in Serbian). 
Official Gazette of the Republic of Serbia, 2011. Regulation on adopting of Implementation Program of the Spatial Plan of the Republic of Serbia from 2010 to 2020 , for the period from 2011 to 2015, Belgrade, No. 102/2011. (in Serbian).

Official Gazette of the Republic of Serbia, 2016. Regulation on adopting of Implementation Program of the Spatial Plan of the Republic of Serbia for the period from 2016 to 2020, Belgrade, No. 104/2016. (in Serbian).

Official Gazette of the Socialist Republic of Bosnia and Herzegovina, 1974. Law on Spatial Planning, Sarajevo, No. 13/1974. (in Serbo-Croatian).

Perišić, D. 1985. About Spatial Planning. Institute of Architecture and Urban \& Spatial Planning of Serbia, Belgrade. (in Serbian).

Redman, L.N. 1983. The Planning Process. Managerial Planning, 31- 6, 24-40.

Republic Agency for Spatial Planning, 2012. Report on Implementation of the Spatial Plan of the Republic of Serbia and the State of Spatial Development in 2011. Republic Agency for Spatial Planning, Belgrade. (in Serbian).

Republic Agency for Spatial Planning, 2013. Report on Implementation of the Spatial Plan of the Republic of Serbia and the State of Spatial Development in 2012. Republic Agency for Spatial Planning, Belgrade. (in Serbian).

Republic Agency for Spatial Planning, 2014. Report on Implementation of the Spatial Plan of the Republic of Serbia and the State of Spatial Development in 2013. Republic Agency for Spatial Planning, Belgrade. (in Serbian).

Republika Srpska Institute of Statistics, 2013. Census of population, households and dwellings in $\mathrm{BH}$ 2013, on the territory of Republika Srpska - Preliminary results. Republika Srpska Institute of Statistics, Banja Luka. (in Serbian and English).

Republika Srpska Institute of Statistics, 2015. Statistical Yearbook of Republika Srpska 2015. Republika Srpska Institute of Statistics, Banja Luka. (in Serbian and English).

Stefanović, N. 2011. Implementation models of spatial plans (Unpublished doctoral thesis). University of Belgrade, Faculty of Geography, Belgrade. (in Serbian with English summary).

Stefanović, N., Milić, Đ. 2012. Theoretical considerations about implementation and implementation models of spatial plans. In: Stojkov, B., Dobričić, M. [eds.], Spatial planning in Serbia - current topics, Republic Agency for Spatial Planning, Belgrade, 42-67. (in Serbian with English summary).

Vujošević, M. 2004. Rationality, legitimacy and implementation of planning decisions - newer theoretical interpretations and lessons for planning in transition. Institute of Architecture and Urban \& Spatial Planning of Serbia, Belgrade. (in Serbian).

Wannop, A.U. 1995. Regional Imperative: Regional Planning and Governance in Britain, Europe and the United States. Regional Studies Association, London. 